\title{
TOLERÂNCIA À DESSECAÇÃO DE PÓLEN DE BERINJELA ${ }^{1}$
}

\author{
LEOMARA VIEIRA DE FRANÇA²; WARLEY MARCOS NASCIMENTO3; \\ RICARDO CARMONA4; RAQUEL ALVES DE FREITAS ${ }^{5}$
}

\begin{abstract}
RESUMO - A alta demanda por sementes híbridas tem estimulado pesquisas que asseguram a oferta destas, como é o caso da manipulação de grãos de pólen. Assim, em estudo conduzido na Embrapa Hortaliças, no ano de 2006, objetivou-se determinar a tolerância à dessecação dos grãos de pólen berinjela 'Ciça'. Para isso foi utilizado pólen fresco (testemunha) e pólen seco em recipiente de alumínio fechado com 300 gramas de sílica gel e em dessecador, ambos por períodos de 24 e 48 horas em ambiente de laboratório. Os respectivos grãos de pólen foram os polinizadores da linhagem feminina. Foi avaliado o pegamento de fruto, a produção e a qualidade fisiológica de sementes através de: massa de 100 sementes, teste de primeira contagem, germinação, emergência de plântulas e envelhecimento acelerado. Concluiu-se que grãos de pólen toleram dessecação até 4,7\% de umidade e com teores de água entre $4,7 \%$ a $47,2 \%$ proporcionam boa produção de sementes sem afetar sua qualidade fisiológica.
\end{abstract}

Termos para indexação: Solanum melongena, produção de sementes, qualidade fisiológica.

\section{DESICCATION TOLERANCE OF EGGPLANT POLLEN}

\begin{abstract}
The high demand for hybrid seeds has stimulated research to assure their supply and this includes pollen grain manipulation. The object of a study at the Embrapa Vegetable Institute in 2006 was to determine the tolerance of eggplant pollen grains of the 'Cica' variety to desiccation. Fresh pollen (control) and dry pollen were placed in closed aluminum containers with silica-gel and also in a laboratory desiccator for 24 and 48 hours. The pollen grains were used to pollinate female plants and the fruit set, production and physiological seed quality were measured from the first count test of a 100 seeds, including germination, seedling emergence and accelerated ageing. The results demonstrated that pollen tolerates desiccation up to $4.7 \%$ moisture content. Pollen grains with moisture content ranging between $4.7 \%$ and $47.2 \%$ gave good seed production without any affect on their physiological quality.
\end{abstract}

Index terms: Solanum melongena, seed production, seed physiological quality.

${ }^{1}$ Submetido em 12/03/09. Aceito para publicação em 04/12/2009.

Parte da Dissertação de Mestrado do primeiro autor apresentado à Faculdade de Agronomia e Medicina Veterinária da Universidade de Brasília.

${ }^{2}$ Eng. Agr., MS., Doutoranda do Programa de Pós-graduação em Ciência e Tecnologia de Sementes da Universidade Federal de Pelotas, Caixa Postal 354, CEP 96010-900, Pelotas, RS, agro_leomara@yahoo.com.br.
${ }^{3}$ Eng. Agr, PhD., Pesquisador da Embrapa Hortaliças, Caixa Postal 218, CEP 70359-970, Brasília, DF, wmn@cnph.embrapa.br.

${ }^{4}$ Eng. Agr, PhD., Professor Adjunto da Universidade de Brasília, Caixa Posta104508, CEP 70910-970, Brasília, DF, rcarmona@unb.br.

${ }^{5}$ Eng. Agr., Dr., Analista de Nível Superior da Embrapa/SNT Uberlândia, CEP 38400-700, Uberlândia, MG, raquel.freitas@.embrapa.br . 


\section{INTRODUÇÃO}

Conhecer a capacidade germinativa (viabilidade) dos grãos de pólen do progenitor masculino em espécies vegetais é fundamental no processo de hibridação artificial. A planta quando bem manejada apresenta pólen com alta capacidade germinativa. Este pólen pode ser utilizado tanto em sistema de conservação de germoplasma, da mesma forma em que se utilizam sementes e partes vegetativas (Yates e Sparks, 1990), como em programas de melhoramento genético e produção de sementes com a utilização da hibridação artificial.

No caso da cultura da berinjela, a hibridação artificial tem sido bastante importante para o mercado brasileiro, sendo que atualmente os híbridos de berinjela são os mais cultivados, pois além da heterose, apresentam grande produtividade, qualidade superior, uniformidade das plantas e frutos, maior precocidade e maior adaptação a diferentes condições edafoclimáticas (Ribeiro et al., 1998).

A preservação da viabilidade dos grãos de pólen, durante curto ou longo período de conservação, envolve a redução do grau de umidade, a utilização de temperaturas mais baixas durante o armazenamento e, em alguns casos, a exclusão do oxigênio do interior dos recipientes de armazenamento (Akihama et al., 1979). Com isto, as variações da taxa respiratória e de outros processos metabólicos são minimizadas, tornando o pólen, então, quase inativo ou dormente durante o tempo em que estiver armazenado (Snyder e Clausen, 1974). Soma-se a isto, a redução da proliferação de micro-organismos e, consequentemente da deterioração dos grãos de pólen.

Segundo Martins et al. (1981), quanto menor o período e maior a temperatura de armazenamento, maior poderá ser o teor de água dos grãos de pólen. Assim, pólen com baixo teor de água (8 a 10\%), propicia boa longevidade, independente do método de armazenamento (Sprague e Johnson, 1977). Em vários trabalhos, a viabilidade do pólen armazenado é mantida quando o mesmo está seco (Sousa, 1988); neste caso, há uma diminuição do risco de formação intracelular de cristais de gelo, formados em temperaturas abaixo do ponto de congelamento $\left(0^{\circ} \mathrm{C}\right)$ (Barnabás e Rajki, 1976). A formação destes cristais pode romper os tecidos celulares, possivelmente devido à lesões na membrana celular (Polito e Luza, 1988), o que afeta a viabilidade do pólen.

Para Weatherhead et al. (1978), a secagem do pólen antes do armazenamento é desnecessária, uma vez que foi possível a produção de sementes botânicas de batata utilizando pólen fresco. Entretanto, segundo Akihama et al. (1978), também é possível produzir sementes de pêra e pêssego utilizando pólen seco e armazenado.

A secagem é a forma de reduzir o teor de água do pólen. Esta deve ser realizada com cuidado, não permitindo que a temperatura de secagem exceda $28^{\circ} \mathrm{C}$ (Argerich e Gaviola, 1995). Pólen muito seco pode reduzir sua capacidade germinativa por perder água de constituição. Algumas técnicas para retirar umidade dos grãos de pólen são: a liofilização (McGUIRE, 1952; Akihama et al., 1978) e a utilização de substâncias higroscópicas, como a sílica gel (Ahlgren e Ahlgren, 1978; Pereira et al., 2002), solução de cloreto de sódio (Ferreira et al., 2007), ou outras, desde que acondicionadas em recipientes que proporcionem a condição de vácuo (dessecador).

A quantidade de água que pode ser retirada dos grãos de pólen varia com a espécie. Em milho, por exemplo, a retirada de água reduz sua viabilidade (Ferreira et al., 2007), enquanto em beterraba, essa viabilidade é mantida (Hecker et al., 1986). O pólen tolera dessecação até certo ponto, sendo que a perda da viabilidade em diferentes espécies tem sido correlacionada com a perda de água e a manutenção do estado de desidratação em condições naturais e de laboratório (Linskens e Cresti, 1988; Nepi e Pacini, 1993; Lisci et al., 1994). A gramínea Festuca arundinaceae apresenta pólen parcialmente desidratado com viabilidade reduzida ou quase nula após a deiscência das anteras (Pacini et al. ,1997).

Conforme descrito no parágrafo anterior, é possível que os grãos de pólen apresentem um comportamento variável entre as diferentes espécies com relação à tolerância à dessecação, semelhante ao observado em sementes ortodoxas, recalcitrantes e intermediárias. Assim, pode ser que grãos de pólen de algumas espécies não tolerem a desidratação, tendo por consequência sua capacidade de armazenamento bastante curta quando comparada a outras com longevidade de grãos de pólen ortodoxos. Esse comportamento em sementes ainda não é bem esclarecido e em grãos de pólen, menos ainda.

$\mathrm{Na}$ literatura, dificilmente são mencionadas formas de secagem do pólen, e nos casos em que isso ocorre (McGUIRE, 1952; Kwan et al., 1969; Akihama et al., 1978; Ferreira et al., 2007; Silva Filho, 2007) não existe uma descrição detalhada da metodologia utilizada e do teor de água residual presente nos grãos de pólen. Isto dificulta sua repetibilidade e utilização prática na produção de sementes híbridas. Assim, o objetivo deste trabalho foi determinar a tolerância à dessecação de grãos de pólen de berinjela. 


\section{MATERIAL E MÉTODOS}

O trabalho foi desenvolvido na Embrapa Hortaliças, Brasília, DF, no período de junho a outubro de 2006. Foram coletadas flores após a antese (abertas) da linhagem masculina do híbrido de berinjela 'Ciça' e o pólen dessas flores foi extraído com auxílio de vibrador elétrico. A umidade dos grãos de pólen foi reduzida através do acondicionamento dos mesmos em microtubo "eppendorf" $(1500 \mu \mathrm{l})$ abertos e submetidos à secagem em dessecador e em recipiente de alumínio fechado com 300 gramas de sílica gel, ambos por períodos de 24 e 48 horas em ambiente de laboratório. Em cada microtubo foram colocados grãos de pólen extraídos de 30 flores. Como testemunha, foi utilizado pólen fresco (extraído das flores e não submetido à dessecação).

Foi determinado o grau de umidade dos grãos de pólen, na base úmida, para todos os tratamentos, adotando o método da estufa utilizado para a quantificação do teor de água de sementes (Brasil, 1992). Em virtude de os grãos de pólen serem pequenos e leves, foram confeccionadas taras de papel alumínio com diâmetro de $1,5 \mathrm{~cm}$ e $1,0 \mathrm{~cm}$ de altura, onde foi colocada uma porção de grãos de pólen (quantidade aproximada de pólen extraído de 20 flores). As pesagens foram realizadas em balança de precisão com três casas decimais $(0,001 \mathrm{~g})$ e, em seguida, as amostras foram colocadas em estufa a $105{ }^{\circ} \mathrm{C} \pm 3{ }^{\circ} \mathrm{C}$ por 24 horas, sendo após esse período pesadas novamente. $\mathrm{O}$ grau de umidade foi determinado por meio da média de três repetições.

Com os grãos de pólen frescos e secos, foram polinizadas manualmente 10 flores emasculadas, para cada tratamento, da linhagem feminina da cultivar 'Ciça', no estádio de botão. O estigma de cada flor emasculada foi saturado com os grãos de pólen, não tendo uma quantidade certa de pólen por flor, visto que é inviável determinar a quantidade de pólen por flor devido ao tamanho dos grãos. Após 15 dias da polinização, foi determinada a porcentagem de pegamento de frutos nas plantas. Os frutos de berinjela para consumo são colhidos entre 30 e 45 dias após a polinização, entretanto para produção de sementes essa colheita é realizada mais tardiamente, pois o ponto de maturidade fisiológica da semente ocorre depois da maturidade do fruto, pois este após maduro continua translocando reserva para a semente. O ponto de maturidade fisiológica das sementes ocorre normalmente quando o fruto perde o brilho e sua coloração passa de vinho-arroxeado para castanho-amarelado. Em virtude disso, sessenta dias após a polinização, os frutos produzidos e com coloração castanho-amarelado foram colhidos e colocados em repouso por 15 dias em local sombreado, seco e arejado (Nascimento et al., 2000). Após esse período, os frutos foram cortados em pequenos pedaços, adicionado água, e passados duas vezes em um equipamento desintegrador de polpa, para fins de extração úmida das sementes. As sementes foram então submetidas a uma secagem em estufa, inicialmente a $32^{\circ} \mathrm{C}$ por 24 horas e em seguida a $40^{\circ} \mathrm{C}$ por 24 horas, mantendo as sementes com umidade de aproximadamente 5\%. As seguintes características foram avaliadas imediatamente após a extração:

Número de sementes por fruto: as sementes extraídas dos frutos foram pesadas e, com base na massa de 100 sementes, estipulou-se o número de sementes por fruto.

Massa de 100 sementes: quatro subamostras de 100 sementes de cada tratamento foram pesadas, sendo a média dos resultados expressa em gramas (g).

Teste de germinação: o teste foi conduzido segundo as Regras para Análise de Sementes (Brasil, 1992). Foram utilizadas para cada tratamento quatro repetições de 50 sementes, semeadas em caixas plásticas (gerbox) sobre papel umedecido com água, colocadas em germinador com temperaturas alternadas de $20^{\circ} \mathrm{C}$ ( 16 horas $)$ e $30^{\circ} \mathrm{C}$ ( 8 horas), sendo as avaliações realizadas aos 7 (primeira contagem) e aos 14 dias após a montagem.

Teste de emergência de plântulas em substrato: foram utilizadas quatro repetições de 50 sementes de cada tratamento. A semeadura foi realizada em bandejas de poliestireno expandido (isopor ${ }^{\circledR}$ ) de 200 células, contendo uma semente por célula, utilizando substrato comercial Plantmax $^{\circledR}$. O teste foi desenvolvido em casa de vegetação com avaliação aos 32 dias.

Teste de envelhecimento acelerado com solução salina: foi utilizado um gerbox adaptado para formar uma câmara úmida com aproximadamente $76 \%$ de umidade relativa, em que foi adicionado $40 \mathrm{~mL}$ da solução salina na concentração $40 \mathrm{~g} \mathrm{NaCl} / 100 \mathrm{~mL} \mathrm{H}_{2} \mathrm{O}$. Neste gerbox foi colocado uma tela suspensa e nela acondicionadas as amostras de cada tratamento de maneira a constituírem uma camada única de sementes. Cada amostra continha aproximadamente 250 sementes. As caixas gerbox foram mantidas por 96 horas em estufa a $41^{\circ} \mathrm{C}$ (França et al. 2007). Após esse período, as sementes foram submetidas ao teste de germinação, conforme descrito anteriormente, sendo avaliadas após 7 dias.

O delineamento utilizado foi inteiramente casualizado, com quatro repetições, utilizando-se o sistema Sisvar (Ferreira, 2000) para as análises estatísticas. Os dados foram transformados em $(\mathrm{x}+1)^{1 / 2}$, e as médias dos tratamentos comparadas pelo teste de Tukey. Realizou-se regressão 
polinomial para o variável grau de umidade.

\section{RESULTADOS E DISCUSSÃO}

O pólen fresco (recém-extraído) apresentou grau de umidade de 47,2\% (Tabela 1). A secagem por $24 \mathrm{~h}$ no dessecador reduziu a umidade para $10,8 \%$ (perda de 36,4 pontos percentuais de água), enquanto no recipiente de alumínio o teor de água foi reduzido para 17,4\% (perda de 29,8 pontos percentuais de água). O período de $48 \mathrm{~h}$ proporcionou maior desidratação dos grãos de pólen em ambos os recipientes com redução nos teores de água para 4,7\% e 5,3\% nos recipientes de alumínio e dessecador, respectivamente. Observou-se uma redução no teor de água do pólen com o aumento do período de dessecação, independentemente do local de secagem (Figura 1). A secagem foi mais rápida nas primeiras 24 horas em razão do maior teor de umidade inicial nos grãos de pólen.

TABELA 1. Valores médios obtidos no número de sementes (NS), massa de 100 sementes (MCS), testes de primeira contagem (PC), germinação (Ger), emergência de plântulas em substrato (Eme) e envelhecimento acelerado (EA) de sementes de berinjela 'Ciça' oriundas de cruzamentos utilizando grãos de pólen com diferentes graus de umidade.

\begin{tabular}{|c|c|c|c|c|c|c|c|c|}
\hline \multicolumn{2}{|c|}{ Secagem do pólen } & \multirow{2}{*}{ Umidade $(\%)$} & \multirow{2}{*}{ NS } & \multirow{2}{*}{$\operatorname{MCS}(\mathrm{g})$} & \multirow{2}{*}{$\mathrm{PC}(\%)$} & \multirow{2}{*}{ Ger $(\%)$} & \multirow{2}{*}{ Eme $(\%)$} & \multirow{2}{*}{$\mathrm{EA}(\%)$} \\
\hline Local & Período (horas) & & & & & & & \\
\hline Testemunha & - & 47,2 & 1410ab & $0,49 \mathrm{c}$ & $18 \mathrm{a}$ & $61 \mathrm{a}$ & $61 \mathrm{a}$ & $45 \mathrm{a}$ \\
\hline Alumínio & \multirow{2}{*}{24} & 17,4 & $1402 \mathrm{ab}$ & $0,52 \mathrm{a}$ & $24 \mathrm{a}$ & $58 \mathrm{a}$ & $60 \mathrm{a}$ & $46 \mathrm{a}$ \\
\hline Dessecador & & 10,8 & $1653 a$ & $0,49 \mathrm{c}$ & $13 a$ & $51 \mathrm{a}$ & $53 a$ & $32 \mathrm{a}$ \\
\hline Alumínio & \multirow{2}{*}{48} & 4,7 & $917 b$ & $0,49 \mathrm{c}$ & $18 \mathrm{a}$ & $53 \mathrm{a}$ & $42 \mathrm{a}$ & $27 \mathrm{a}$ \\
\hline Dessecador & & 5,3 & $1149 \mathrm{ab}$ & $0,51 b$ & $13 a$ & $51 \mathrm{a}$ & $47 \mathrm{a}$ & $33 a$ \\
\hline & $\mathrm{CV}(\%)$ & & 9,1 & 0,18 & 16,87 & 6,89 & 15,96 & 22,79 \\
\hline
\end{tabular}

Médias seguidas pela mesma letra na coluna não diferem entre si pelo teste de Tukey, a 5\% de probabilidade.

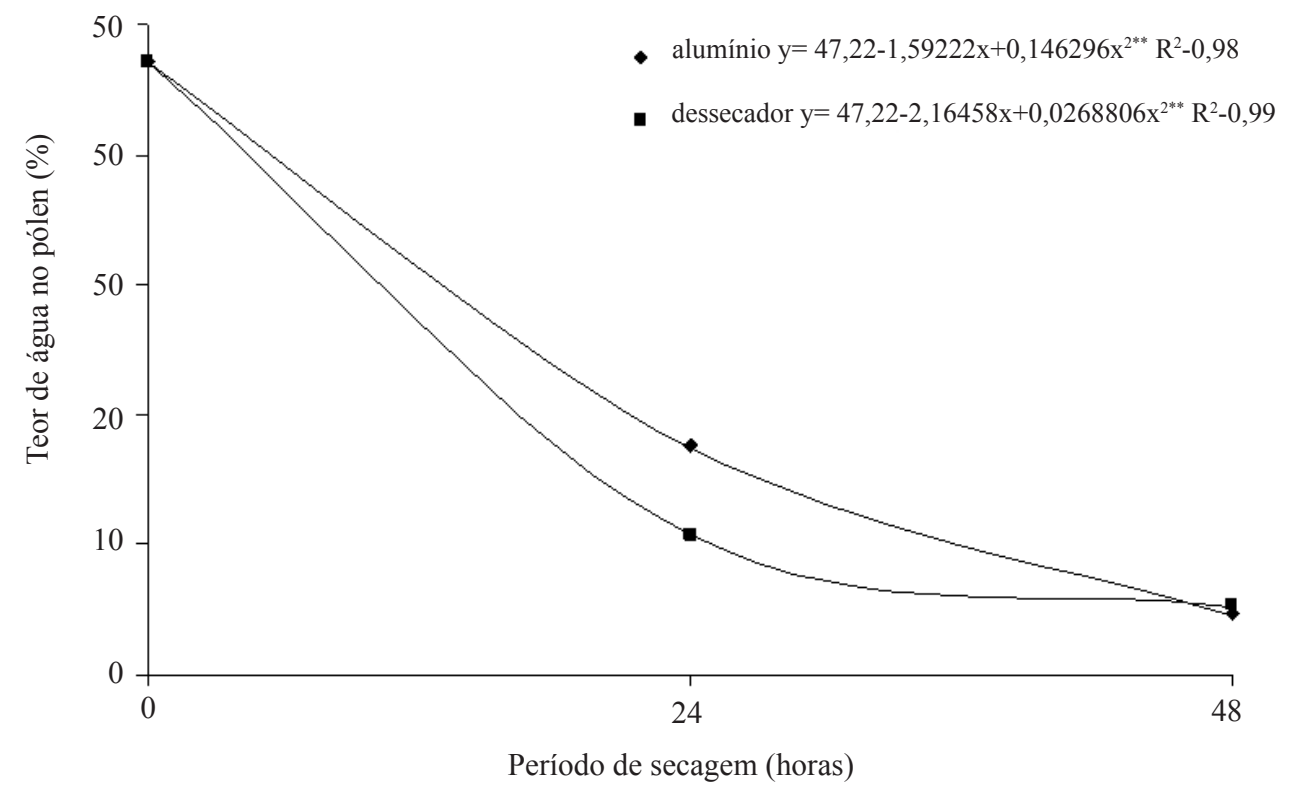

FIGURA 1. Grau de umidade (\%) de grãos de pólen de berinjela desidratados em diferentes recipientes e períodos de secagem. 
Observou-se um excelente pegamento de frutos, independente da utilização de pólen recém-extraído ou seco (dados não apresentados). Os grãos de pólen com 47,2\% de umidade ou secos a $4,7 \%$ proporcionaram $90 \%$ de pegamento de frutos, enquanto nos demais teores de umidade o pegamento de frutos foi de $100 \%$. Esses índices de pegamento de frutos foram superiores aos observados por Akihama et al. (1978) em pêra, os quais obtiveram pegamento de $82 \%$ com pólen seco contendo $5,6 \%$ de umidade.

$\mathrm{O}$ número de sementes por fruto variou significativamente, sendo que o pólen com $10,8 \%$ e com $4,7 \%$ proporcionou maior e menor número de sementes, respectivamente (Tabela 1). Vale ressaltar que, o pólen contendo $4,7 \%$ de água sofreu a maior desidratação (perda de 42,5 pontos percentuais de água). Já os frutos com maior número de sementes foram aqueles polinizados com grãos de pólen secos com umidade mais elevada. Akihama et al. (1978) observaram que o número de sementes de pêra obtido com polinizações realizadas tanto com pólen fresco ou seco foi similar. Segundo Kakizaki, citado por Noda (1980), frutos de berinjela provenientes de polinização cruzada produzem em média 688 sementes; os resultados encontrados no presente trabalho apresentaram médias superiores a esta, sendo que a menor média obtida (917 sementes) foi proveniente de frutos polinizados com grãos de pólen mais desidratados. Essa diferença não é relevante, pois mesmo "saturando" o estigma com pólen, o ovário de cada flor contém uma quantidade diferente de óvulos, e mesmo se todos os óvulos fossem fertilizados, o número de sementes produzidas poderia ser variável, devido inclusive a fatores externos.

Com relação à massa de sementes, os grãos de pólen que apresentaram teores de água de 17,4\% foram os que resultaram o maior valor. Já aqueles com teores de $4,7 \%, 10,8 \%$ e $47,2 \%$ resultaram a menor massa de sementes (Tabela 1). A umidade do pólen, no momento da polinização, parece não ter relação direta com a massa de sementes obtida.

Como observado, houve diferenças significativas com relação à quantidade de sementes produzidas, entretanto estas sementes não apresentaram diferença quanto à qualidade fisiológica (Tabela 1). Comparando a testemunha com os grãos de pólen secos, observou-se que a diferença no grau de umidade não afetou a qualidade das sementes produzidas, e assim a capacidade de fertilização do pólen seco para produção de sementes foi mantida (Tabela 1). Resultados similares foram encontrados por Hecker et al. (1986) com pólen seco (12\%) de beterraba. Assim, a qualidade fisiológica das sementes produzidas utilizando os grãos de pólen com 4,7\% de água foi similar à encontrada nas sementes produzidas utilizando pólen com 47,2\%, entretanto em valor absoluto a qualidade fisiológica (germinação) encontrada foi menor que a mínima exigida pelo MAPA (Ministério da Agricultura Pecuária e Abastecimento) para comercialização que é de $70 \%$ (Brasil, 1986). Para Marcos Filho (2005) a dormência das sementes, independentemente de sua causa, é tanto mais acentuada quanto mais nova for a semente. Dessa forma, é mais intenso em sementes recém-colhidas, podendo ser esse o motivo do baixo valor germinativo das sementes, visto que as sementes foram avaliadas imediatamente após a extração do fruto. Dependendo da espécie e/ou cultivar, a dormência pode durar de poucos dias a vários anos, tendendo diminuir com o tempo.

Aparentemente, existe um nível ideal de umidade do pólen para cada espécie, mantendo-o viável ou não. Para Pseudotsuga menziesii, este valor de umidade situa-se entre 4,0 a 7,0\% (Copes, 1987) e para pólen de Juglans regia, entre 3,2 e 7,0\% (Luza e Polito, 1988). Em geral, o limite máximo de umidade do pólen para diversas espécies, situase entre 20 e $40 \%$. Por outro lado, o limite inferior está estimado entre 1 e $5 \%$, devendo ser utilizado com cuidado, pois pode haver redução de viabilidade a esses níveis mais baixos (Kartha, 1985).

O pólen de berinjela com grau de umidade entre 4,7\% e $47,2 \%$, independente de como esses valores foram atingidos, apresentou viabilidade para produzir semente com qualidade fisiológica aceitável. Entretanto, os grãos de pólen a serem armazenados devem ter uma umidade adequada, pois se muito secos pode haver perda da viabilidade e se muito úmidos pode gerar formação intracelular de cristais de gelo quando os grãos são armazenados sob temperaturas abaixo do ponto de congelamento $\left({ }^{\circ} \mathrm{C}\right)$ (Barnabás e Rajki, 1976).

\section{CONCLUSÃO}

Grão de pólen de berinjela tolera dessecação até 4,7\% de umidade e com teores de água entre 4,7 a 47,2\% proporciona boa produção de sementes sem afetar sua qualidade fisiológica.

\section{REFERÊNCIAS}

AHLGREN, C.E.; AHLGREN, I.F. Viability and fertility of vacuum dried pollen of 5 needle species. Foresty Science, v.24, n.1, p.100-102, 1978. 
AKIHAMA, T.; OMURA, M.; KOZAKI, I. Further investigation of freezer-drying for deciduous fruit tree pollen. In: AKIHAMA, T.; NAKAJIMA, K. (Ed.). Long term preservation of favorable germplasm in arboreal crops. Fujimoto: Fruit tree research station, 1978. p.1-7.

AKIHAMA, T.; OMURA, M.; KOSAKI, I. Long-term of fruit tree pollen and its application in breeding. Tropical Agriculture Research, v.13, n.4, p.238-241, 1979.

ARGERICH, C.A.; GAVIOLA, J.C. Production de semilla de tomate. 1ed., Argentina: INTA-EEA la Consulta, Fascículo 6, 1995. 81p.

BARNABÁS, B; RAJKI, E. Storage of maize (Zea mays L.) pollen at $-196{ }^{\circ} \mathrm{C}$ in liquid nitrogen. Euphytica, v.25, p.747752, 1976.

BRASIL. Ministério da Agricultura e Reforma Agrária. Secretaria Nacional de Defesa Agropecuária. Departamento Nacional de Produção Vegetal. Coordenação de Laboratório Vegetal. Regras para Análise de Sementes. Brasília, DF, 1992. 365p.

BRASIL. Portaria $n^{\circ} 457$, de 18 de dezembro de 1986. (Estabelece os padrões de sementes olerícolas para distribuição,...) Diário Oficial da União, Poder Executivo, Brasília, DF, 23 dez. 1986, p.19653.

COPES, D.L. Long term storage of douglas-fir pollens. Forest Science, v.33, n.1, p.244-46, 1987.

FERREIRA, C.A.; VON PINHO, E.V.R.; ALVIM, P.O.; ANDRADE, V.; SILVA, T.T.A.; CARDOSO, D.L. Conservação e determinação da viabilidade de grãos de pólen de milho. Revista Brasiliera de Milho e Sorgo, v.26, n.2, p.159-173, 2007.

FERREIRA, D.F. Análises estatísticas por meio do Sisvar para Windows versão 4.0. In: $45^{\mathrm{a}}$ REUNIÃO ANUAL DA REGIÃO BRASILEIRA DA SOCIEDADE INTERNACIONAL DE BIOMETRIA, 45., 2000, São Carlos. Anais... São Carlos: UFSCar, 2000. p.255-258.

FRANÇA， L.V.; NASCIMENTO, W.M.; FREITAS, R.A. Accelerated aging test on eggplant seeds. In: $28 \mathrm{TH}$ ISTA CONGRESS/XV CONGRESSO BRASILEIRO DE SEMENTE, 28./15., 2007, Foz de Iguaçu. Anais... Foz de Iguaçu: ABRATES, 2007. p.118.

HECKER, R.J.; STANWOOD, P.C.; SOULIS, C.A. Storage of sugarbeet pollen. Euphytica, v.35, n.3, p.777-783, 1986.

KARTHA, K.K. Cryopreservation of plant cells and organs. Boca Raton: CRC Press., 1985. 276p.
KWAN, S.C.; HAMSON, A.R.; CAMPBELL, W.F. Storage conditions for Allium cepa L., pollen. Journal of the American Society for Horticultural Science, v.94, n.6, p.569-570, 1969.

LINSKENS, H.F.; CRESTI, M. The effect of temperature, humidity and light on the dehiscence of tobacco anthers. Proceedings of the Koninklijke Nederlandse Akademie an Wet ,v.91, p.369-375, 1988.

LISCI, M.; TANDA, C.; PACINI, E. Pollination ecophysiology of Mercurialis annua L. (Euphorbiaceae) an anemophilous species flowering all year round. Annals of Botany, v.74, n. 2, p.125- 135, 1994.

LUZA, J.G.; POLITO, V.S. Cryopreservation of English walnut (Juglans regia L.) pollen. Euphytica, v.37, n.2, p.141-48, 1988.

MARCOS FILHO, J. Fisiologia de sementes de plantas cultivadas. Piracicaba: FEALQ. 2005. 495p.

MARTINS, M.E., PRERA, L.E.H.; KAGEYAMA, P.Y. Manejo de pólen de Pinus para fins de melhoramento genético. Circular Técnica n 128. 1981. Disponível em: $<$ http://www.ipef.br/publicacoes/ctecnica/nr128.pdf $>$. Acesso em: 4 abr. 2007.

McGUIRE, D.C. Storage of tomato pollen. Proceedings of the American Society for Horticultural Science, v.60, p.419-424, 1952.

NASCIMENTO, W.M.; LIMA, L.B.; ALVARES, M.C. Maturação de sementes de híbridos de berinjela. Horticultura Brasileira, v.18, p.1040-1041, 2000. Suplemento.

NEPI, M.; PACINI, E. Pollination, pollen viability and pistil receptivity in Cucurbita pepo. Annals of Botany, v.72, p.527-536, 1993.

NODA, H. Critérios de avaliação de progênies de irmãos germanos interpopulacionais em berinjela (Solanum melongena L.). 1980. 91f. Dissertação (Mestrado em Genética e Melhoramento de Plantas) - ESALQ/USP, Piracicaba.

PACINI, E.; FRANCHI, G.G.; LISCI, M.; NEPI, M. Pollen viability related to type of pollination in six angiosperm species. Annals of Botany, v.80, p.83-87, 1997.

PEREIRA; R.C.; DAVIDE, L.C.; RAMALHO, M.A.P.; ANDRADE, H.B. Alternativas para aumentar a eficiência dos cruzamentos em programas de melhoramento de Eucalyptus. Cerne, v.8, n.2, p.60-69, 2002.

POLITO, V.S.; LUZA, J.G. Low temperature storage of pistachio pollen. Euphytica, v.39, n.3, p.265-269, 1988. 
RIBEIRO, C.S.; BRUNE, S.; REIFSCHNEIDER, F.J.B. Cultivo da berinjela (Solanum melongena L.). Brasília, DF: EMBRAPA-CNPH, 1998. 23p. (Instrução Técnica $\left.\mathrm{n}^{\mathrm{o}} 15\right)$.

SILVA FILHO, J. G. Avaliação da temperatura e do período de armazenamento na conservação de grãos de pólen de tomate (Lycopersicon esculetum Mill), visando a produção de sementes híbridas. 2007. 32f. Monografia (Especialização em Biotecnologia vegetal) - Faculdade JK, Brasília.

SNYDER, E.B.; CLAUSEN, K.E. Pollen handling. In: Schoomeyer, C.S. Seeds of woody plants in the United States. USDA Agricultural Handbook, Whashington: USDA. 1974. p.75-97.
SOUSA, V.A.. Manejo e viabilidade do pólen de $\boldsymbol{E} \boldsymbol{u}$ calyptus spp. 1988. 155f. Dissertação (Mestrado em Engenharia Florestal) - Escola Superior de Agricultura Luiz de Queiroz, Piracicaba, 1988.

SPRAGUE, J.R.; JOHNSON, V.W. Extraction and storage of lobloly pine (Pinus taeda) pollen. In: SOUTHERN FOREST TREE IMPROVEMENT CONFERENCE, 14., 1977. Proceedings... Macon: Eastem Tree Seed, 1977. p.20-27.

WEATHERHEAD, M.A.; GROUT, B.W.W.; HENSHAW, G.G. Advantages of storages of potato pollen in liquid nitrogen. Potato Research, v.21, p.331-334, 1978.

YATES, I.E.; SPARKS, D. Three-year-old pecan pollen retains fertility. Journal of the American Society for Horticultural Science, v.115, n.3, p.359-363, 1990. 